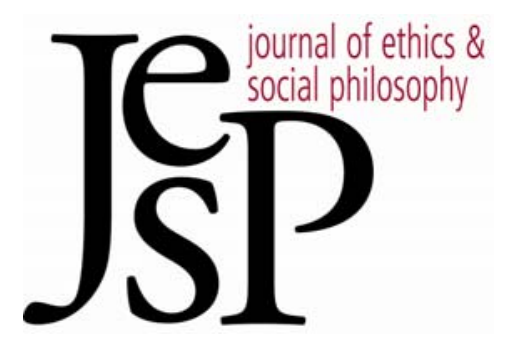

\title{
THE ENFORCEMENT APPROACH TO COERCION
}

\author{
BY SCOTT A. ANDERSON
}

Journal of Ethics \& Social Philosophy

VOL. 5, NO. 1 | OCTOBER 2010

URL: WWW.JESP.ORG

COPYRIGHT (C) SCOTT A. ANDERSON 2010 


\title{
The Enforcement Approach to Coercion*
}

\author{
Scott A. Anderson
}

S TARTING IN THE 1960S, THE CONCEPT of coercion has received sustained attention from philosophers, resulting in a panoply of attempts to explain its nature and significance. Despite the apparent diversity in these efforts, the vast majority of them follow in a line of thinking laid out most influentially by Robert Nozick in 1969 which, roughly speaking, identifies coercion with the way one agent can put pressure on the will of another by means of threats. ${ }^{1}$ This way of approaching the topic - I will call it the "pressure" approach - has come to seem wholly obvious to many subsequent writers, though it differs markedly from an earlier understanding of the nature of coercion that it largely supplanted. This earlier approach to coercion - which I will call the "enforcement" approach - regards coercion as a kind of activity by a powerful agent who creates and then utilizes a significant disparity in power over another in order to constrain or alter the latter's possibilities for action. This power differential may be used to put pressure on the coercee's will, but additionally it might work by simply interdicting or disabling agents, or disrupting various possibilities for action more systematically. Such systematic disruption can be achieved by incarceration or capital punishment, as well as via longstanding threats that alter broad patterns of activity, and not just specific actions. This approach sees differential power relations as essential to coercion so, on this approach, some ways in which agents put pressure on other agents that do not arise from significant power differentials will not register as coercion.

Choosing between the two approaches may depend on what questions one is trying to answer, and how the concept of coercion figures in them. Coercion is frequently thought to figure into determining a state's legitimacy and authority; it is also thought to be morally problematic, and so to be wrongful if not specially justified. Concern with coercion also arises due to its tendency to restrain human freedom and to curtail responsibility. Much of the recent work on coercion has been tailored to one or another of these issues, with a predominance of interest in the question of how coercion affects responsibility for actions taken under coercion. Whatever success has been achieved in tackling this question, it is now apparent that the pressure ap-

\footnotetext{
* This paper is better for the input of numerous readers, including Elizabeth Brake, Dominic Lopes, Martha Nussbaum, Alan Wertheimer, the members of the University of Chicago Law School's Law and Philosophy Workshop, and several editors and anonymous referees. The initial draft of this paper was completed while I was in residence at the University of Chicago Law School, the support of which is gratefully acknowledged. A precursor version of this paper was presented at Simon Fraser University's Philosophy Department Colloquium, whose feedback (especially David Zimmerman's) was also very helpful.

1 Robert Nozick, "Coercion," in Philosophy, Science, and Method: Essays in Honor of Ernest Nagel, Sidney Morgenbesser, Patrick Suppes and Morton White (eds.) (New York: St. Martin's Press, 1969): 440-472.
} 
proach to coercion has encountered significant difficulty in explaining the social and political significance that has long been attributed to coercion. ${ }^{2}$ Hence, part of the interest in elaborating and defending the enforcement approach, I will argue, is that it is more helpful than the pressure approach for assessing the social and political significance of coercion: whether or not one agent puts pressure on another's choice of actions, the use of the kind of power tracked by the enforcement approach is a matter of considerable social significance, and something that helps explain both the state's authority as well as its proper limits.

If the enforcement approach did just this much, it would then increase the range of theoretical treatments of the concept in a way that is useful for social and political philosophy. It would also bolster the view, held by theorists such as Alan Wertheimer and Mitchell Berman, that claims about coercion should be considered as applying only within a specific context, and that "the single unified conception of coercion that theorists seek ... is of little, if any, normative significance." 3 However that may be, I will argue that the enforcement approach is fundamental relative to the pressure approach in that its analysis of coercion accounts for the plausibility and usefulness of the pressure approach: insofar as the pressure approach is able to identify instances of coercion correctly, it is because it tacitly assumes that coercion works in the way the enforcement approach depicts explicitly. The commonsense view that coercion works by putting pressure on an agent's will thus spotlights an epiphenomenal aspect of coercion, rather than its most important explanatory aspects. In failing to attend to these factors explicitly, the pressure approach is liable to miscategorize cases, or else to leave the work of the account to potentially contentious normative judgments that would themselves require a separate, sustained defense. So even for purposes such as assessing the morality of coercion and its effects on agent responsibility, there is value in applying the analysis of the enforcement approach to such questions. For these reasons the enforcement approach deserves to be more clearly understood and more widely applied than it has been of late.

\section{Two Approaches to Coercion}

Instead of positing two competing "concepts" of coercion, I will describe instead two distinct approaches to the subject of coercion, which lead to dif-

\footnotetext{
2 For one indication of the difficulty here, see William Edmundson, "Is Law Coercive?" Legal Theory 1 (1995): 81-111; and Edmundson, Three Anarchical Fallacies: An Essay on Political Authority (New York: Cambridge University Press, 1998), chs. 4-6. For further discussion, see Section 4, part B.

3 Mitchell Berman, “The Normative Functions of Coercion Claims," Legal Theory 8 (2002): 45-89, at 46. See also Alan Wertheimer, Coercion (Princeton: Princeton University Press, 1987), 189-91, 310.
} 
ferent ways of understanding what "coercion" means. ${ }^{4}$ Four questions will bring out their distinctive aspects:

(1) What need the coercer do in an episode of coercion?

(2) What are the conditions on the relationship between coercer and coercee that make it possible for one to coerce the other?

(3) How is the coercee's situation affected by the coercer's activities?

(4) How are instances of coercion individuated, ontologically?

\section{A. Coercion as Pressure on the Will}

Coercion is commonly and intuitively associated with the mundane phenomenon of feeling pressure to do something that one does not want to do. Theorists have recently portrayed coercion principally as a way in which one agent puts psychological pressure on another to act or not act in some particular way by means of threats that alter the costs and benefits of acting. They then typically develop tests to determine which sorts or degrees of pressure will count as coercive and what follows from such a judgment. ${ }^{5}$ Such accounts also typically proceed by surveying a range of cases that seem intuitively to involve coerced actions, and abstracting from them common features. The following sorts of proposals are routinely, if not universally, judged to be coercive in this literature: a drug dealer's threat to withhold a regular customer's supply unless he beats up another person'; a threat to destroy someone's beloved car unless he commits a murder'; a dry cleaner's threat to refuse to return a customer's laundry unless she pays an unjust $\$ 10$ premium8; a blackmailer's threat to reveal one's infidelity unless one pays a

4 To avoid possible confusion, I note that both approaches to coercion are "agentic": they treat coercion as an intentional act of an agent. They are thus distinct from theories that treat coercion as a structural or relational fact about social order. Michel Foucault's work is frequently mentioned in discussions of coercion and exemplifies this latter way of thinking about coercion, but it falls outside of the debates discussed in this essay. For more on this distinction, see Terence Ball, "Two Concepts of Coercion," Theory and Society 5 (1978): $97-$ 112.

5 Representative prominent accounts of coercion fitting the pressure approach include Robert Nozick, in "Coercion"; Harry Frankfurt, "Coercion and Moral Responsibility," in T. Honderich (ed.), Essays on Freedom of Action (London: Routledge \& Kegan Paul, 1973), 65-86; H. J. McCloskey, "Coercion: Its Nature and Significance," Southern Journal of Philosophy 18 (1980): 335-352; David Zimmerman, "Coercive Wage Offers," Philosophy and Public Affairs 10 (1981): 121-145; Jeffrie Murphy, "Consent, Coercion, and Hard Choices, Virginia Law Review 67 (1981): 79-102; Joel Feinberg, Harm to Self (New York: Oxford University Press, 1986), chapters 23-24; Joseph Raz, The Morality of Freedom (Oxford: Oxford University Press, 1986), 148-154; Alan Wertheimer, Coercion; Berman, "Normative Functions"; with Nozick, Frankfurt and Wertheimer the most influential of these.

${ }^{6}$ Nozick, "Coercion," 447-449.

7 Michael J. Murray and David F. Dudrick, "Are Coerced Acts Free?" American Philosophical Quarterly 32 (1995): 109-123, at 120.

8 Berman, "Normative Functions," 69-71. 
substantial sum;; and a millionaire's offer to pay for surgery for a gravely ill child if only the child's mother agrees to become the millionaire's mistress. ${ }^{10}$ While these accounts differ in their classification of cases, the tendency of this approach is to expand the concept to capture many different ways an agent can pressure the will of another coercively.

With respect to the four questions above, the pressure approach sees coercion as follows:

(1) The coercer's role: The coercer communicates implicitly or explicitly a conditional proposal, typically involving a threat, against another, accompanied by some demand regarding the latter's future actions. ${ }^{11}$ While some accounts require more, such as particular intentions that may go beyond what is communicated, the coercer's role is by and large communicative.

(2) Conditions on the relationship of coercer to coercee: Coercion is possible because the coercer's threat is psychologically potent for the coercee. In particular, the coercee regards the coercer's threat as credible, and regards the outcome portended as sufficiently undesirable that action to avoid the outcome is warranted. The coercee's subjective appreciation of the situation is determinative of the coercer's effect on the coercee.

(3) Impact on the coercee's situation: The costs and benefits of actions open to the coercee are negatively altered by the coercer's threat, compared to how the payoff structure stood before the threat was made, making some actions less desirable as choices.

(4) The ontology of coercion: Instances of coercion are taken to coincide with the actions of a coercee that have been altered by the coercer in the direction intended by the coercer. "Coercion" is thus a "success" term: if the recipient of a proposal intended to coerce does not subsequently alter her behavior from the course it was on prior to receiving the proposal, then the recipient was not coerced by it, and no coercion took place. (Or, to encompass the possibility of attempted but unsuccessful coercion, they may say that the would-be coercer acted coercively; what remains constant, however, is

\footnotetext{
9 Grant Lamond, "Coercion, Threats, and the Puzzle of Blackmail," chapter 10 in Harm and Culpability, A. P. Simester and A. T. H. Smith (eds.) (Oxford: Clarendon Press, 1996), 215238.

10 Feinberg, Harm to Self, 229-233.

11 The words "threat" and/or "threaten" can be used to refer both to unconditional propositions and to conditional propositions accompanying a demand. For the sake of clarity, I will use "threat" or "threaten," sans phrase, to refer only to situations in which an agent $(\mathrm{P})$ makes a demand to another $(\mathrm{Q})$ that $\mathrm{Q}$ do (or not do) some action $(A)$ and accompanies this demand with a claim or indication that if and only if the demand is unfulfilled, P will act or bring about events contrary to Q's interests. These uses can be distinguished from "plain threats" - i.e., unconditional claims by $\mathrm{P}$ that $\mathrm{P}$ will act contrary to Q's interests at some point in the future, regardless of other contingencies - but plain threats will play no role in the analysis of coercion here.
} 
that coercion is identified in terms of particular acts that the coercee does or does not take under threat.) ${ }^{12}$

This description of the pressure approach can be found operating in almost all recent philosophical writing on coercion, though such accounts do vary, and these claims are often tacit in them, perhaps because they seem so obvious.13 Taking these features for granted, most recent philosophical effort has concentrated on analyzing what makes a proposal a threat rather than an offer. ${ }^{14}$ Since both propose to create an alteration in the costs and benefits of acting, a question arises as to how to define a baseline against which to judge the proposal as improving or worsening an agent's prospects for action. Debates over the role of moral judgment in theories of coercion often get start-

12 Not all pressure accounts accept the success condition; however, the identification of instances of coercion with specific coerced acts/omissions is widespread. However, the success condition appears to be more common than not, with Nozick and McCloskey being two of many who incorporate such a success condition into their definitions of coercion, while Wertheimer accepts it tacitly, since he only compasses cases in which coercion is successful. For further citations and arguments that this restriction is problematic, see my "How the Coercer Got Away: Evaluating Nozick-Style Accounts of Coercion," unpublished manuscript, available upon request.

13 Arguably all of the most prominent philosophical analysts of coercion in the last 40 years subscribe to the pressure approach to coercion. In addition to those essays cited in note 5 above, the following offer accounts fitting the pressure approach: Michael Bayles, "Coercive Offers and Public Benefits," The Personalist 55 (1974): 139-144; Hans Oberdiek, "The Role of Sanctions and Coercion in Understanding Law and Legal Systems," American Journal of Jursiprudence 21 (1976): 71-94; Donald Van De Veer, "Coercion, Seduction, and Rights," The Personalist 58 (1979): 374-381; Theodore Benditt, "Threats and Offers," The Personalist 58 (1979): 382-384; Martin Gunderson, “Threats and Coercion," Canadian Journal of Philosophy 9 (1979): 247-259; Cheyney C. Ryan, “The Normative Concept of Coercion,” Mind 89 (1980): 481-498; Michael Gorr, "Toward a Theory of Coercion," Canadian Journal of Philosophy 16 (1986): 383-406; Peter Westen, “Freedom' and 'Coercion' - Virtue Words and Vice Words," Duke Law Journal 1985 (1985): 541-593; Mark Fowler, "Coercion and Practical Reason," Social Theory and Practice 8 (1982): 329-355; Nancy Tuana, "Sexual Harassment: Offers and Coercion," Journal of Social Philosophy 19 (1988): 30-42; Craig L. Carr, "Coercion and Freedom," American Philosophical Quarterly 25 (1988): 59-67; Murray and Dudrick, "Are Coerced Acts Free?"; and Michael Rhodes, Coercion: A Nonevaluative Approach (Atlanta: Rodopi, 2000). Felix Oppenheim, in Dimensions of Freedom (New York: St. Martin's Press, 1961), offers a forerunner of the pressure approach.

${ }_{14}$ Both are bi-conditional proposals that aim to alter action by creating differentials among the costs and benefits of acting. In addition to Nozick and Wertheimer, see Scott Altman, "Divorcing Threats and Offers," Law and Philosopby 15 (1996): 209-226; and Andrew Hetherington, "The Real Distinction Between Threats and Offers," Social Theory and Practice 25 (1999): 211-242.

Some recent accounts hold that conditional offers can also coerce, though this is a minority view. See, e.g., Robert Stevens, "Coercive Offers," Australasian Journal of Philosophy 66 (1988): 83-95. While the enforcement approach does not regard threatening as necessary or sufficient for coercing, it is concerned with uses of the kind of power that underlies the ability to make significant, credible threats - namely, the ability to broadly inhibit another agent's actions. Offers do not in general make use of this particular sort of power. Still, if there are coercive offers, the enforcement approach would recognize them by the particular sort of use of power involved. 
ed here, in setting the baseline. The baseline question arises, however, because the proposals here are conceived in terms of their effects on the costs and benefits as perceived by the coercee, rather than in more concrete terms related to what exactly is being threatened, or how one agent comes to be in a position to threaten another. These latter considerations receive nearly no attention from theories taking the pressure approach to coercion even though, as I will argue, they are crucially important to it.

\section{B. Coercion as Enforcement}

The other approach to coercion seems to have gone out of fashion about the time of Nozick's analysis (and possibly due to its influence). ${ }^{15}$ This view holds that coercion is best understood as one agent's employing power suited to determine, through enforceable constraints, what another agent will or (more usually) will not do, where the sense of enforceability here is exemplified by the use of force, violence and the threats thereof to constrain, disable, harm or undermine an agent's ability to act. ${ }^{16}$ One sign of the distinctiveness of this approach is that it regards grabbing, manacling and imprisoning a person to prevent him from acting as paradigmatically coercive, while the pressure approach regards such actions as entirely outside of the bounds of its idea of coercion. ${ }^{17}$

Instead of surveying a broad range of cases in which one might feel coerced, the enforcement approach analyzes a few paradigmatic areas of activity in which powerful agents use directly their ability to disrupt the ability of others to act, or (more typically) leverage that ability by means of threats.

15 For documentation of Nozick's influence on this subject, see my "How the Coercer Got Away."

16 "Force" refers throughout to physical means used to move, manipulate, invade or constrain a human body. "Violence" is a special case where force is used intentionally to injure, incapacitate or cause pain to a person through physical effects on her body. "Violence" here omits damage to property, but includes uses of drugs or other chemicals to inflict harm or pain. Note also that people frequently welcome and invite others to use force on them (e.g., to transport them), although invited violence is fairly unusual.

17 McCloskey, following Nozick, represents the more common view which rejects the use of the term "coercion" to describe direct uses of force. "When subjected to force, one does not act at all; rather one is acted upon; things are done to one or via one. ... The person who is subject to force, the physical force of another, or to natural forces, has things happen to him. ... By contrast, the coerced person acts...." McCloskey, "Coercion," 340. Others, like Michael Bayles and Martin Gunderson, accept the term "coercion" for some uses of force, but draw a categorical distinction between it ("occurrent coercion") and "dispositional coercion" (i.e., coercion by threat). Harry Frankfurt, Joel Feinberg and Grant Lamond, similarly distinguish sharply between "physical" and "psychological" compulsion or coercion. See Michael Bayles, "A Concept of Coercion," in J. R. Pennock and J. W. Chapman (eds.), Nomos XIV: Coercion (Chicago: Aldine-Atherton, Inc., 1972), 49-62; Martin Gunderson, "Threats and Coercion"; Frankfurt, "Coercion and Moral Responsibility"; Feinberg, Harm to Self, pp. 190-192; Lamond, "Coercion, Threats, and the Puzzle of Blackmail." Though these latter theorists allow the term "coercion" to apply to direct uses of force, in all cases the focus of their analysis is on the use of threats, which is treated as bearing little or no relationship to coercion via force. 
Such cases encompass police utilizing their powers to arrest and jail suspects; the law's ability to inhibit certain behaviors by criminalizing them, or its ability to enforce contracts or civil laws through police powers; robbers and $\mathrm{Ma}$ fiosi who utilize similar powers for less noble goals; and men who use violence or intimations of violence to impose themselves sexually on women or other men. Other cases may be counted as coercion according to their likeness to these kinds of examples. These uses of coercion are also, not accidentally, ones of central importance for establishing social order and ensuring justice, in part because such powers also pose significant risks to these goods. The enforcement approach is thus especially concerned to describe and explain how certain forms of power operate in structuring society while also giving rise to some of its biggest challenges.

Elaborated in terms of the four questions posed above, the enforcement approach holds:

(1) The coercer's role: The coercer is either responsible for creating a power differential over the coercee, or else leverages some pre-existing differential in power over the coercee for which the coercee is not at fault. ${ }^{18}$ The coercer employs that power over the coercee to constrain substantially the latter's practical possibilities. This typically occurs in one of two distinctive ways:

a. the coercer can directly disable or constrain the coercee from being able to act or (less commonly) cause the coercee to do something; or

b. the coercer can make a threat to use these powers or other powers suitable to necessitate action by the coercee, unless the coercee meets some condition.

(2) Conditions on the relationship of coercer to coercee: Coercion is possible because of the coercer's willingness and ability to draw upon powers over another agent (relationally conceived), which the coercee is unable or unwilling to use against the coercer. Such powers may inhere in these agents either individually or as representatives of two different kinds of actors known to stand in this sort of power relationship (say, law enforcement officer and private citizen, or armed robber and victim).

(3) Impact on the coercee's situation: The coercee confronts a situation in which some possibilities for action have been immediately foreclosed and/or one in which the agent regards it as practically necessary to do what the coercer demands because it is practically necessary to avoid the situation the coercer threatens to bring about or to exit the situation once it has been brought about.

(4) The ontology of coercion: Acts of coercion are coincident with the activities of coercers aiming to constrain or alter the activities of others by drawing upon the distinctive powers needed for coercion. Coercive acts may

${ }^{18}$ This formulation is intended to exclude cases where the weaker agent is herself responsible for putting herself under the thumb of the more powerful agent. See section 2 below. 
affect indefinitely many of a coercee's activities, some particular activity or activities, or none. An attempt at coercion can fail to be coercive if the coercee successfully neutralizes the coercer's power by preemption, defensive means or coercive retaliatory threats. A coercer's aim in coercing may also be foiled if the coercer's activities fail to constrain the activities of the coercee as the coercer had intended. But this sort of failure does not necessarily imply that coercion has not been employed. (For instance, making bluff threats, intending them to be taken as sincere, is an act of coercion whether or not such threats achieve their aim.)

A window on this approach is provided by J. R. Lucas, who writes of coercion in 1966 that,

[W]e are concerned with the enforcement of decisions: we are considering the conditions under which decisions will be carried out regardless of the recalcitrance of the bloody minded. We therefore define force in terms of bloody-mindedness, of what happens irrespective of how recalcitrant a man is, of what happens to him willynilly. Force, then, we say, is being used against a man, if in his private experience or in his environment either something is being done which he does not want to be done but which he is unable to prevent in spite of all his efforts, or he is being prevented, in spite of all his efforts, from doing something which he wants to do, and which he otherwise could have done by himself alone. A man is being coerced when either force is being used against him or his behaviour is being determined by the threat of force. ${ }^{19}$

And:

[1] mprisonment is the paradigm form of coercion.... Even if it were not regarded as a penalty, it would still be effective in frustrating the efforts of the recalcitrant to prevent a judicial decision being implemented. ${ }^{20}$

The enforcement approach, as represented by Lucas, seeks to track uses of the kind of power that some agents have over others by being able to obstruct, disable or undermine broadly the latter's ability to act, "willy nilly." 21

${ }^{19}$ J. R. Lucas, The Principles of Politics (Oxford: Clarendon Press, 1966), p. 57. (Emphasis in the original.) Lucas defines "force" more broadly than merely physical means, but his subsequent discussion indicates that physical force is his principal concern.

20 Ibid., 60.

${ }^{21}$ That is, whether the targeted agent is of a mind to cooperate or not. Lucas voices a view that was at the time shared widely among prominent political theorists. Hans Kelsen directly connects the coercive order of the state to its use of force: "As a coercive order, the law is distinguished from other social orders. The decisive criterion is the element of force - that means that the act prescribed by the order as a consequence of socially detrimental facts ought to be executed even against the will of the individual and, if he resists, by physical force." The Pure Theory of Law, Max Knight (trans.) (Los Angeles: University of California Press, 1967), 34. (Original German first edition published 1934; second edition, 1960.) Kelsen later identifies as coercive the detention of criminal suspects, the insane and political enemies, as well as the confiscation or destruction of property. Ibid., 40-41. Alf Ross defines a national law system as "the rules for the establishment and functioning of the state machinery of force" in On Law and Justice (London: Stevens and Sons Limited, 1958), 34. Christian Bay writes: 
On this account, the principal mode of coercion is prevention; inducement to perform specific acts typically follows on the ability to prevent many or even all other acts. When an agent acquires the power to inhibit another's action broadly, the powerful agent has the ability to alter radically what is practically necessary for the weaker agent, thus explaining the sense of necessity invoked when coercees claim, e.g., that "I had no choice" or "he made me do it." Such power is well exemplified by the motivated use of force or violence, or threats thereof, because the ability to wield force and violence allows one to impose grave disabilities on others. Nonetheless, force/violence do not exhaust the range of such powers, since there are other forms of power an agent can acquire that allow one to impose broad disabilities on another, or (in a way I will discuss later) to impose practical necessities on another.

\section{Some Immediate Comparisons}

The pressure approach sees coercion from the coercee's perspective and attempts to characterize it in a way that can explain the feeling that one is forced to do what one does not want to do. A seeming advantage of this approach is that it is fairly ecumenical about what sorts of threats can be the source of such pressure; anything disadvantageous to the coercee's interests seems fit to be used to cause a coercee to alter her actions. It also provides a fairly straightforward ontology, in that it connects instances of coercion to particular acts taken or foregone because of the pressures threats can create. As $\mathrm{H}$. J. McCloskey writes, "the coerced person acts"; coercion works by impacting her will. ${ }^{22} \mathrm{By}$ implication, if there is no impacted action, then there is no coercion.

By contrast, the enforcement approach holds that coercion can occur even when an agent feels no overt pressure to do as the coercer demands: for instance, a law threatening punishments for murder will count as coercive on this approach even if, say, those who obey it would do so even if there were no punishments for violating it, while the others prove to be undeterred by

When a person wants to do something (or remain passive) and is forcibly restrained (pushed), we speak of "coercion." The same word is used also if he is still able to do what he wants but has to suffer as a consequence a severe punishment or the loss of a very important reward. It is also convenient to consider less severe or "noncoercive" punishments under this heading, which refers to restraints on what I call social freedom.

Bay, The Structure of Freedom (New York: Atheneum Press, 1965), 16-17. (Originally published 1958.) Also, "[C]oercion in this study means (a) the application of actual physical violence, or (b) the application of sanctions sufficiently strong to make the individual abandon a course of action or inaction dictated by his own strong and enduring motives and wishes." Ibid., 93. In a collegiate primer on law, Dennis Lloyd writes, "[ $[$ s law really conceivable, or at least possible in any practical sense, when it is not ultimately backed by effective force? Certainly the force of law is and seems always to have been linked with rules which are capable of being enforced by coercion; the hangman, the gaoler, the bailiff, and the policeman are all part of the seemingly familiar apparatus of a legal system." The Idea of Law (Middlesex, England: Penguin Books Ltd., 1970), 35 (first published in 1964). In Lloyd's book's index, the entry for coercion reads, "See force, sanction."

22 See note 17 , supra. 
those punishments. Including direct uses of force to prevent actions can also complicate the picture, since direct intervention frequently prevents a broad spectrum of otherwise possible activities, so it may be impossible to say exactly what acts the coercee did or did not perform on account of this use of coercion. Moreover, the enforcement approach will find that some acts induced by some threats are actually not coerced, even when they meet the standards of a pressure account. As a result, the ontology of coercion favored by this approach is likely to seem less straightforward: coercion need have no particular effect on any particular coercee and, in some cases, its effects may not be straightforwardly enumerable in terms of actions taken or foregone.

Much of the recent debate over coercion has centered on whether an account of coercion must rely intrinsically on some normative presuppositions (is intrinsically "moralized"), or whether such a theory can be developed from purely positive premises ("non-moralized"). Although this debate will be joined at various points in the subsequent discussion (especially at the end of section 2), for now note that the enforcement approach can identify at least some instances of coercion - those I have described as paradigmatic cases - without relying on any particularly contestable normative presuppositions to do so. As we shall see, the enforcement approach does not rule out appealing to normative judgments for understanding how coercion works in some cases, but neither does it support the view that judgments about the occurrence of coercion are intrinsically moralized.

The divergence in these two approaches is worth noting in its own right, if only to recognize and avoid ambiguous use of the term "coercion." But is this then merely a verbal dispute? After elaborating the enforcement approach more fully in section two, section three will argue that its divergence from the pressure approach carries several important advantages for ethics and social and political philosophy. To be clear: the pressure and enforcement approaches do overlap in their judgments about many of the central cases of coercion, so judged extensionally the difference between the two approaches may not appear major. But the two approaches diverge considerably in where they locate the gravamen of coercion and, consequently, in what they can say about its distinctiveness as a social phenomenon and its place in ethical and political theory..$^{23}$

\section{The Enforcement Approach Elaborated}

The enforcement approach invokes the notion of power, which raises some immediate worries. Interpersonal power is of course hard to assess and comes in many forms. The enforcement approach identifies coercion with the power to prevent an agent's actions broadly, which is closely related to

${ }^{23}$ For further discussion of how to understand the difference between these two approaches, see my "Of Theories of Coercion, Two Axes, and the Importance of the Coercer," Journal of Moral Philosophy 5 (2008): 294-422. 
the ability to create new practical necessities for her. Does this mark off a distinctive, significant kind of power? Here is one way to describe the bounds of this category: Take as a starting point several exemplars of this sort of power and some one-step extensions of these central cases. Killing, gravely injuring, shackling and closely confining someone are methods that inhibit virtually all of the meaningful actions an agent can take, and do so for prolonged periods, if not forever. For shorter durations, drugging, electrically stunning and manhandling can have similar constraining effects. These are paradigmatic cases of the sort of power at issue. Generalizing from these models, we may also consider other ways of imposing significant disabilities on someone. Most obvious are denying someone the collected material means needed to live or carry out ordinary activities (food, shelter, tools), or exiling or ostracizing her. These latter techniques are likely to need bolstering by the more direct physical means noted above, as, for instance, someone who is denied material goods by edict could simply appropriate them from others if otherwise unimpeded. But once an effective system of physical coercion is in place to establish a system of ownership of tangible and intangible property, one can then deny access to these sorts of goods as a way of constraining an agent's activities.

We might also consider including within this sort of power more limited ways of disabling a person, such as through imposing broad legal disabilities or social disgrace. These and other possible instantiations of the kind of power I am describing can be judged according to the extent to which one agent can at will prevent another from undertaking significant ranges of activity, as in the paradigmatic examples above. ${ }^{24}$

A person can find oneself holding power over someone else through the latter's own imprudence or just bad luck, but this way of coming into power over another does not normally generate the sort of concerns that the enforcement approach aims to track. By way of illustration, if a person is trapped in a deep hole, a sole rescuer at ground level can exercise a great deal of control over what the trapped person can do. But to judge the significance of the situation, we need to know how the trapped person got there and what responsibility the would-be rescuer bears for the predicament. There is a big difference between finding someone whose own foolishness or bad luck landed him in a hole, and digging the hole and pushing the person in it. Of course, one can act badly by exploiting the predicament of someone in weakened circumstances (a possibility that is frequently limited by competition among exploiters). But there is a much more pressing social concern when one agent accumulates a general power suited to stop others, and then

${ }^{24}$ One relatively new possible variety of such power is the power to exclude parties from the credit and banking system. Though less dramatic or comprehensive than physical power, power over an individual's access to financial services - such as banking, credit and payment services - could be used to severely constrain that individual's possibilities for action. This power is magnified when it resides in the hands of relatively few financial and bureaucratic institutions, and especially when they act in concert. 
uses it to put another in such weakened circumstances. Thus, in addition to the powerful agent's possession of the relevant sort of power, we need to describe coercion in terms of the coercer's intentions to acquire and then employ such power to constrain broadly the activities of others. Whenever an agent intentionally accumulates the power needed to constrain others broadly (say, by arming herself), and then employs or threatens to employ such powers in this way, it amounts to a paradigmatic instance of coercion of the sort that political philosophy does well to track.

Between cases in which power is acquired in order to coerce and cases of self-inflicted weakness, there are other possible ways people come to possess power over others. Some people are just larger, stronger and physically more able, while others are smaller, weaker and more physically vulnerable. Innate differences in these sorts of capacities can put some in position to harm or constrain others without any effort or intention by the stronger party. Others occupy offices in which power of the relevant sort attends performance of the office. In these circumstances, the difference between coercion and exploitation may be harder to mark, but a lot depends on what use the stronger party makes of his strength and whether that use generates (or threatens to generate) significant incapacity on the part of the weaker party. For instance, a large man and a small, unarmed woman can interact on equal terms in virtually all regards so long as the man does nothing to leverage the fact that he is able to harm, constrain or manhandle her at will - that is, during such time as he provides meaningful assurances that he is not disposed to use such means. If, instead, he indicates a willingness to use his physical advantage to constrain or disable her, then this power advantage becomes a live matter that can strongly color further interactions between them. Similar considerations may apply when someone has recourse to substantial power in an official capacity. Insofar as an official constrains her activities to those dictated by her institutional role, she does not coerce (although she may also be part of a larger agent - e.g., the state - which does coerce through her office). But if she chooses to use her powers at her personal discretion or for her individual ends, then it makes sense to regard such power use as suited for coercion. 25

A further worry arises from the possibility of bluff threats: successful threateners need not actually possess the ability and willingness to enforce their threats, but need only be perceived to have such power. And if a threatened party acquiesces when faced with a credible bluff, surely she has been coerced, even if the coercer lacked the relevant power. This seems to indicate a lacuna in the enforcement approach which does not trouble the pressure

25 This last example may lead one to suppose that a normative account of coercion is required after all, but this would be too hasty as a general conclusion. While a normative analysis may be needed to determine whether an official is using her powers arbitrarily, this is a special case, not the typical one. See further the arguments at the end of this section. 
approach, since the latter focuses on the coercee's subjective assessment of her situation.

This objection requires fuller elaboration of where a coercer's power to threaten resides. Whereas some coercers (say, states and Mafias) can usually draw upon their own past history of enforcing their threats, other coercers without such reputations must either demonstrate their powers directly, or else draw upon their connection or resemblance to others who have possessed and used such powers in the past. The ability to make such a connection depends on how like or unlike the coercer is to the sort of agent the coercee would reasonably expect to have this power. This is to say that the basis of the power to issue successful threats frequently lies outside of the coercer him or herself, in a shared background understanding of, for instance, what similar agents have done in the past when they have exercised such powers, especially in response to threats that have been rejected. Even agents who actually possess the powers they threaten to use often rely on such a shared background: unless their targets have a personal history with them, or other proofs of the agent's powers, those targets will typically rely on knowledge of, for instance, what other police, Mafiosi, armed gunmen or rapists have done in the past when their demands have been defied. ${ }^{26}$

While this might seem to resort to a subjective approach after all, bluff threats can work only if in general there is a real difference in power between agents like the coercer and coercee. When a bluffer credibly threatens someone, he typically relies upon the history of past acts by agents at least superficially similar to the bluffer. We might say that the bluffer is a free rider, of sorts, on the commons of enforcement powers. While free riding is often more profitable than contributing one's fair share, this is possible only so long as such a commons exists. If too many bluffers draw on this shared resource without contributing, it is liable to collapse. So when one attempts to coerce via a bluff threat, one draws upon the power of those who have demonstrated the ability and willingness to use their powers in the past, especially when defied. Hence, the possibility of coercion by bluff does not undercut the connection between coercing and enforcing; it just locates that connection in a broader context than is usually made explicit.

One might worry, however, that associating coercion with just this one way of conceiving social power omits a variety of other coercive activities. Kidnapping, blackmail, non-violent extortion, duress and economic pressure are routinely regarded as coercive, yet it seems that to make such compelling threats, one need not possess the power to broadly disrupt the threatened party's ability to act; instead, these threats (merely) work against the interests of the coercee, rather than her ability to act. Hence, these cases appear not to fit the picture of coercion painted by the enforcement approach.

${ }^{26}$ By the same token, if the coercer's powers are located in abilities unfamiliar to the coercee, his threat may remain incredible no matter how terrified the target ought to be. 
However, the enforcement approach does help to analyze such threats and to make some important distinctions among them. First, note that not all such threats are equal. One distinction worth making with respect to cases of blackmail, extortion and some economic threats is between cases where the threatened party's weakness is self-inflicted and those where the victim is vulnerable due to broader patterns of social power in which she occupies a disadvantaged position. Some blackmailing and extortion exploit weaknesses that are the result of the victim's imprudence, immorality or criminal behavior, while others exploit weaknesses that arise due to factors beyond the victim's control. For an instance of the latter sort, if one's homosexuality or ancestry are secrets that, if broadcast, could undermine one's safety or ability to function in society, then a blackmailer could lever this sort of power against someone, and the enforcement approach could recognize such threats as similar to its more central cases. But in cases where an agent has cloaked her bad actions with secrecy, blackmail that leverages such self-inflicted weakness is of quite different and arguably lesser interest, since the blackmailee herself put the blackmailer in power over her. Some such cases may resemble the more paradigmatic ones if a revelation of the blackmailee's secret would be severely disabling to him, but even then we need not treat them the same. ${ }^{27}$ So the enforcement approach distinguishes among cases of blackmail with respect to the source and extent of the power used by the blackmailer against the blackmailee, and thereby explains how blackmail can amount to coercion, and why even more often it seems to be coercive.

In cases of kidnapping and violent threats against third parties, it is useful to distinguish between the party over whom the coercer has direct power, and the party on whom a demand is made and on whose will pressure is brought to bear. (Call the former agent the "hostage," and the latter the "oblique target.") The enforcement approach has no trouble finding that such acts are coercive in their use of power against the hostage. Its apparent difficulty is in deciding whether a threat against a third-party hostage can subject an oblique target to coercion. The threatener lacks direct power over the oblique target; he can merely pressure her by attacking her interests in the hostage's safety. Still, there are at least two ways to extend the enforcement approach's analysis to capture such cases. First, if the oblique target serves as the agent of the hostage, then we need not count the oblique target herself as coerced, but can say rather that the hostage is coerced and that the oblique target's actions are necessitated only insofar as she acts on the hostage's behalf. Second, in some cases where the oblique target acts on her own behalf, her actions may be necessitated by obligations to safeguard the hostage. If,

27 There are numerous accounts of the nature of blackmail in the legal and philosophical literature, manifesting dissensus about what is wrong with it, and even about whether it should be a crime. The "paradox of blackmail" remains puzzling because the threatened actions involved in blackmail are not only frequently legal in themselves, but also possibly socially salutary. For a sample of the range of views on this topic, see the essays collected in a symposium on blackmail in the University of Pennsylvania Law Review 141 (1993): 1565-2168. 
for instance, parents and loved ones are necessitated by obligations to prevent such harms to those in their care, then an agent who uses violence and threats of violence can constrain not just the actions of the direct target, but also those bound to prevent such harms. This would assimilate such cases to the more central ones of the enforcement approach. We might bolster this view by noting that such threats might succeed even if the oblique target had no special affection for the hostage, so long as she understands herself to be obligated to do what she can to prevent harm. Conversely, we might deny that an oblique target who merely feels affection for the hostage or who acts out of self-interest is necessitated, or therefore coerced, to act to save him. This distinction may omit some cases that intuitively seem to be ones of coercion, but these will be those in which the oblique target merely feels compelled to act to save the hostage but is under no obligation or other necessity to do so. If we fail to distinguish acting from an obligation or other necessity here from acting out of affection/desire/self-interest, then this is liable to license claims of coercion by anyone who disapproves of what another is doing and who feels compelled to intercede to prevent it. ${ }^{28}$ Enlargement of the concept in this direction dilutes it and may account for some of the doubts recently expressed about its general salience and implications.

Lastly, with regard to economic threats - such as a threat to refuse to trade with another - it is again useful to draw distinctions among them, according to the degree of power the threatener manifests with his threat. When circumstances make it possible for one agent or a few colluders to prevent someone from obtaining the goods needed to engage in wide ranges of activities (or at least a few crucial ones), then they can threaten to prevent someone from achieving most other ends. Such situations are relatively rare, but arise, for instance, when there is a monopoly or monopsony on one side of a trading arrangement, especially with regard to some crucial economic factor, such as food, water, land, housing, banking, education, medical care or employment. In environments where numerous economic agents provide the various crucial goods and services, it is harder for one agent to make threats that, if executed, would truly constrain another party's access to those same goods on terms that are in line with their true, underlying costs. But in any case, when such power can be marshaled by one agent against another, the enforcement approach can recognize it as coercion, given its similarity to the paradigmatic cases. When this is not the case, then it is not clear that one agent or several colluders can make credible economic threats that their target need take seriously as more than a matter of (in)convenience.

Before concluding this section, I hope to ward off one further objection by elaborating on the ambition of the enforcement approach to offer a non-

28 Thus we can and should deny, I think, that anyone was coerced into paying money to "save Toby," a rabbit whose owners threatened to kill and cook him unless those who objected to his owners' doing so would pay $\$ 50,000$ to save the rabbit. For coverage of this Internet-based ploy, see http://www.msnbc.msn.com/id/7406483/ (as of Sept. 7, 2010). 
moralized account of coercion, and the advantages and soundness of doing so. Because coercion is generally thought to carry important normative implications, it has seemed to many that an account of coercion would have to rely upon moral or other normative considerations in order to classify cases accurately and thereby to support those implications. An account that eschews such moral judgments is liable, it may be supposed, to misclassify cases and, in particular, to find coercion where it should not. For instance, some theorists allege that armed self-defense should not count as coercive, since the act of threatening (or even harming) an unjust attacker is not itself wrongful, and these accounts hold that coercion occurs only when a threat is made wrongfully (or at least is pro tanto wrongful).29 Other skeptics might point out that power of the sort on which the enforcement approach focuses is suited to many uses that can affect the actions of others without coercing them. So they may urge that normative standards are required for an account to be able to distinguish usefully between coercive and non-coercive uses of such power. For instance, William Edmundson describes a "98-pound weakling" who manages to build his physical strength to the extent that the local bully ceases to find it appealing to bully him; Edmundson suggests that this accrual of strength and the ensuing change in the bully's behavior should not be regarded as the bulked-up weakling coercing the bully, whereas one might imagine the enforcement approach would see it as such..$^{30}$

Yet it is not obvious that the enforcement approach need retrench to allay these worries. Admittedly, it would allow that uses of force or threats of such in self-defense - even against unjust attackers - could be coercive, but it is far from obvious that such classification would be absurd, or that confusions follow from it. Such aggressive self-defense would likely be regarded as justified coercion, of a sort that the law standardly authorizes, but the technique involved and its social interest are no different for being justified. Note that if such a technique were used for less important purposes (say, to prevent someone cutting ahead in a queue), few would object to regarding it as coercive, even if the action it prevented was itself unjustified. So the fact that the enforcement approach counts such cases as coercive, though moralized accounts might not, does not yet prove that a moralized account of coercion is needed. On the other hand, the enforcement approach need not accept that all employment of deterrence power amounts to coercion. So insofar as the 98-pound weakling's new strength and defensive capacity is sufficient to dissuade his tormentors, we need not hold that they have been coerced. Rather, the enforcement approach can distinguish between the use of such power to block or thwart attacks through (purely) defensive measures and the use or threatened use of such powers to broadly disable a would-be at-

${ }^{29}$ Ryan has argued that in threatening an assailant with death in order to defend oneself or a loved one against rape, it would be absurd to hold that one has thereby coerced the assailant to relent. See Ryan, “The Normative Concept of Coercion,” 483.

30 This worry (and the illustrative example) was raised by an anonymous referee for this journal. Edmundson's example is found in his Three Anarchical Fallacies, 82-83. 
tacker. There is of course reason to worry that defense can shade into offense in the course of a fight, and that there are many shades of gray in such situations. But the difference between defending against attack versus preparing and/or making an attack is an important difference with numerous implications for the possibility of peaceful, harmonious co-existence, so it is one that political philosophy does well to take seriously. It is not, however, particularly a moral distinction; it rather has to do with an agent's aims and intentions, and the techniques she is prepared to use. So the enforcement approach need not treat all accumulations or uses of power that affect the actions of others as on a par; nor need it invoke moral judgments in order to establish such distinctions.

The broader issue invoked by these cases is the relationship of political philosophy to moral philosophy and whether it is possible and/or fruitful to attempt to define fundamental political concepts in terms that avoid contentious moral presuppositions. While we seem to have no trouble believing that the core of the concept "murder," for instance, can be defined in purely factual terms, theorists have doubted whether "coercion" is similarly suited to a positive analysis. ${ }^{31}$ On purely methodological grounds, there is reason to try to model coercion (if indeed it is foundational to political philosophy) and like concepts in ways that avoid drawing upon contentious moral premises..$^{32}$ The test of whether an account like the one advocated here succeeds will be whether it helpfully analyzes and classifies central cases, offers some direction for how to settle more borderline cases and explains why they have the implications that are thought to attend coercion.

With respect to the first two considerations, the enforcement approach to coercion depicted here is in its fundamentals non-moralized: we can recognize when force and violence are used (or threatened) intentionally for the purpose of constraining broadly the activities of another, without evaluating their justifiability. That said, the enforcement approach need not deny that normative judgments may come into determining some of the facts relevant for assessing, say, one agent's power over another (as the discussion of kidnapping above indicates). Given that morality and other forms of normativity play roles in helping us to organize our societies and lives into various cooperative arrangements, there are no doubt many ways in which normativity or morality can come into understanding how one agent can exercise power over another. We can also admit that some related concepts, such as contractual duress, are specifically matters defined by law, and so necessarily depend on normative premises. But these admissions should not lead us to think that the concept as it appears in traditional legal and political theory needs a mor-

31 Advocates of a moralized approach include Wertheimer, Berman, Raz, Ryan and Hetherington; those who oppose (or avoid) it include Frankfurt, Gorr, Feinberg and Zimmerman.

32 For a discussion of the stakes of this debate, see David Zimmerman, "Taking Liberties: The Perils of 'Moralizing' Freedom and Coercion in Social Theory and Practice," Social Theory and Practice 28 (2002): 577-609. 
alized or other normative analysis - at least to understand its most basic uses and its relationship to state authority. The next section argues that the approach to coercion described so far is better able than the rival pressure approach to explain the workings of coercion and to properly identify instances widely recognized as coercive. The following section will argue that this account does indeed explain some of coercion's most important implications.

\section{The Importance of Power Dynamics in Coercion}

To cement the case for the importance of the enforcement approach, I will argue that, to the extent that the pressure approach appears to be a viable alternative to the enforcement approach, its viability depends on assuming that things stand between coercer and coercee in exactly the way the enforcement approach describes. If one does not or cannot make such assumptions, then, even in cases where significant pressure is felt, there will frequently be good reasons to deny that coercion is at work. But coercion is also possible without the use of pressure: we should and often do count as coercion a number of interactions in which one agent constrains the actions of another through other means. Hence, I will argue, the enforcement approach is better suited to track factors that explain how coercion works and why it is significant.

Since the pressure approach is concerned only with threats, my discussion will focus on coercion by threat. Although some coercive threats clearly put pressure on the will, not every threat is suited to do so. What makes a threat a source of pressure on a will? At a minimum, a threat's significance would seem to depend on the conjunction of two factors: the threat's credibility (the likelihood that the threatener can and will execute the threat) and the magnitude of the harm or disadvantage threatened. If a threat is either incredible or of no great consequence, then it should not create coercive pressure and should therefore fall outside the extension of the concept. This leads us to investigate the conditions underlying the credibility and magnitude of threats.

\section{A. Credibility}

Pressure accounts almost never explain what determines whether a threat is credible. On those occasions when this condition is elaborated, it is usually expressed in terms of the coercee's beliefs and actions. For instance, looking at a situation in which $\mathrm{P}$ has threatened $\mathrm{Q}$ with adverse consequences if $\mathrm{Q}$ does some action A, Nozick posits seven necessary and sufficient "conditions for coercion." 33 The key provision here that tracks the credibility of P's threat seems to be $5^{\prime}$ :

33 One may question the attention to Nozick's account here, rather than to more recent discussions such as Wertheimer's. Nozick's account has been remarkably influential, and numerous others have explicitly accepted and/or adapted it in its wake. Many others have 
(5') Part of Q's reason for not doing A is to avoid (or lessen the likelihood) of the consequence which $\mathrm{P}$ has threatened to bring about or have brought about. ${ }^{34}$

In short, $\mathrm{Q}$ must believe that doing as $\mathrm{P}$ demands will alter the likelihood that P's threatened consequence will occur; if $\mathrm{Q}$ does not believe that $\mathrm{P}$ could and would execute his threat, then Q would likely not believe that acting as P demands would help to "avoid" the threatened consequence. So Nozick attends to the credibility of a coercive threat by tracking its effect on the recipient's predictions about the consequences of his acting.

One might suppose that we could assess a threatener's credibility by looking at what the threatened party believes the threatener will do, which may of course be based on that party's assessment of the coercer's powers and intentions. Yet a threat's credibility is not merely the fact that its recipient gives it credence. For one thing, the threatened party might be wildly irrational about what the threatener is willing or able to do. While some might make threats that exploit such irrational beliefs, threats that depend on the threatener's irrationality should be distinguished from normal coercion, since they can be rendered impotent by mere rational epistemic improvements. (This is not to deny that exploiting such irrationality could be immoral.) But even when irrationality is not a problem, credibility is not strictly an epistemic matter. Rather, a threatener's credibility will depend in part on a set of dynamic, relational facts relevant to judging the power differential between the threatener and threatened, and thus will include considerations of the threatened party's own powers, desires and intentions.

To see this, consider a schematic case of the sort that Nozick and perhaps all pressure theorists will agree will count as one of coercion. ${ }^{35}$ Suppose Jones owns a car of some considerable value; Smith demands that Jones give Smith $\$ 50$, threatening that he will smash Jones' car with a sledgehammer if Jones refuses. On Nozick's account, we could say that Smith's threat is credible if Jones believes that Smith is more likely to smash the car if Jones refuses to pay than if he pays. But this likelihood is not a static, given fact about Smith. To see this, consider the factors elicited by the following questions:

been drawn to it through them. Even though there are notable disagreements among those who have followed Nozick (especially over how to characterize threats), the features I attend to here are repeated throughout the accounts I am classifying as manifesting the pressure approach, including Wertheimer's.

${ }_{34}$ Nozick, "Coercion," 441-445. 5' embellishes Nozick's first formulation of condition 5 and replaces it in his analysis.

35 On some accounts, we may need to stipulate further that Jones has a right that Smith not harm his car, or that Smith's threat is immoral on some grounds; such stipulations are unobjectionable but should play little or no role in understanding why the imagined case might be coercive. The case here is adapted from one found in Murray and Dudrick, "Are Coerced Acts Free?" 
(1) Why can't Jones minimize Smith's threat by blocking, disabling or disarming Smith, or by safeguarding himself and his property from Smith's reach (say, by keeping the car in a garage)?

(2) What are the costs and benefits to Smith of executing his threat against Jones, and under what circumstances?

(3) Why can't Jones retaliate to inflict equal or worse damage on Smith?

(4) Why can't Jones rely upon third parties (such as the police or courts) to deter Smith from executing his threat, or to require Smith to compensate Jones for damages?

Pressure accounts like Nozick's tend to conflate the content of the coercer's threat with the actual structure of the resulting situation, as though the threat is definitive of the relations between coercer and coercee, and of the options open to the coercee. Doing so suppresses a number of the powerbased factors that determine whether a threatener and his threat are capable of coercing. For instance, the first question makes the point that there may be a variety of ways for the threatened party to avoid suffering the execution of the threat: meeting a threatener's demand might not be the only one. If the threatened party can easily safeguard himself and his property, disarm the threatener, block execution of the threat or disable the threatener, and do so without further repercussion, then the fact that the threatened party believes that meeting the coercer's demand makes it less likely that the threat would be executed does not imply that the threat is suited to coerce. Were the target of the threat to acquiesce to it in such circumstances, we might reasonably deny he was coerced into doing so. So if Jones could undermine Smith by simply keeping the car in his garage or if it were safe and easy to disarm Smith, then Jones should not be thought to be pressured into paying Smith's demand. If, as may be expected, defensive measures of these sorts are not available to Jones, or if Jones is unwilling to employ them, then such facts and what explains them are also part of what accounts for the credibility of Smith's threat. Quite commonly, Jones' inability to deflect Smith's threat will be explained by facts such as that Smith is generally more powerful than Jones and therefore able to defeat Jones' countermeasures.

The other three questions bring to light considerations that might affect a threatener's willingness to execute his threat if defied, and to refrain from executing it otherwise. Such willingness should not be assumed: executing a threat often entails costs to the threatener, sometimes significant ones. If the target of the threat has defied the threatener's demand, there may be no benefit, and considerable costs, to executing the threat at that point and therefore it may be irrational to do so. Sometimes executing one's threat may yield tertiary benefits (e.g., it might enhance the threatener's reputation for ruthlessness, or give him joy in harming his target). But if executing the threat is independently valuable to the threatener, then these would motivate in favor of executing the threat regardless of whether the target complies with the 
threatener's demand. ${ }^{36}$ If a coercer has more incentive to enforce his threat when defied than otherwise, there are two likely explanations for this: First, the threatener may be in the business of making threats, and having a reputation for enforcing them predictably rather than capriciously would be important to the coercer's broader projects. States and Mafias are in this position, though not most other agents. Second, the coercer may be able to achieve his ends by enforcing his threat, but at greater cost than through the compliance of the threatened party. Robbers and bouncers are often in this position, since gaining compliance from their targets is the easy way to achieve their ends, while physical force provides a fallback option. Threateners can also take advantage of the fact that agents who are confronted with serious threats may have difficulty determining quickly (as may be necessary) what the threatener's capabilities and incentives are with respect to enforcing his threat. Given imperfect information, many nominally serious threats may be given credence which they otherwise would not merit.

The dynamic power relations between threatener/threatened can also undermine a threatener's credibility when the threatener would be at significant risk of retaliation if he executes the threat. Pressure accounts generally take for granted that the target of a threat lacks the wherewithal to retaliate for harms incurred, yet this need not be the case. If the threatened party or its allies (such as the state) can in turn neutralize or reverse the threatener's gains, inflict damage or otherwise inhibit the threatener's future activities especially if this can be done cheaply - then a rational threatener should be more hesitant to execute his threats, even if willing to make them initially. If the threatened party has an advantage in power over the threatener, then even if the threatener could execute his threat, the threatened party could make this much less likely by showing a willingness to retaliate after the fact, or to call on others who could do so in his stead. These considerations are particularly relevant for less extreme threats. If executing a threat kills or seriously disables the target, there may be no great likelihood of retaliation. But executing a lesser threat typically leaves open a possibility of retaliation. To understand how the enforcement of lesser threats might be rational requires, then, a comparison of the powers of the parties involved (at least if we can assume that the parties involved are rational). If the threatener does not enjoy a general advantage in power over the threatened party, then some further explanation is required for why the possibility of retaliation does not undermine the threatener's credibility.

Applying these considerations to our example, clearly it is often easy to destroy property and harm people; so Smith likely has the wherewithal to

36 This describes the paradox of deterrence - a topic that is remarkably little discussed in the literature dedicated to coercion. See generally Thomas Schelling, The Strategy of Conflict (Cambridge: Harvard University Press, 1960). 
execute his threat. ${ }^{37}$ The example as stated, however, gives no indication as to why Jones cannot usefully threaten significant retaliation against Smith, nor why Smith is undaunted by the prospect of civil and criminal intervention after the fact. Perhaps Smith's threat is bolstered by Jones' expectation that the state would intervene more forcefully against himself than against Smith. My point is not that the possibility of retaliation necessarily undermines a threat's credibility, but rather that these sorts of dynamic relations of power must figure into any calculation of how reliably a particular threat can reasonably create pressure. These factors are not simply givens, but are sometimes at least partly under the control of agents such as Jones or the state, so one should not regard the credibility of a threat as something that can be read off of the surrounding static facts.

\section{B. Motivational Magnitude}

To explain a threat's ability to alter actions - which is central to the pressure approach - the content of a threat must contain an incentivizing element. But a coercive threat involves not just any incentive: in particular, offers (i.e., proposals that are not threats) are widely held to be non-coercive. In Nozick's formulation, this incentive is modeled in his condition (7):

(7) Q believes that, and P believes that Q believes that, P's threatened consequence would leave Q worse off, having done A, than if Q didn't do A and P didn't bring about the consequence. ${ }^{38}$

In meeting the threatener's demand, the threatened party aims to minimize her losses, where the pressure to do so is measured by the magnitude of the loss avoided. In other words, threats render particular acts or omissions less choice-worthy by increasing their relative costs. But is such an alteration in costs necessary or sufficient to explain the coerciveness of coercive threats, as the pressure approach suggests? No: such alterations should be recognized as epiphenomenal, rather than constitutive of coercion. What does the work instead is the coercer's ability (i.e., power) to generate such alterations at will, and his willingness to do so. Hence it is a mistake to key our understanding of coercion to presence or absence of pressure itself.

Take the sufficiency issue first. For one agent to affect negatively the payoff structure of another's possible actions is, by itself, not a remarkable phenomenon, nor one that is easily suited to objective assessment. If "threats" are just claims that the threat maker will do something that disadvantages another, then this category would include teachers threatening to penalize late work, customers threatening not to shop at a store if it raises its prices, and friends threatening not to attend a party if $N N$ is invited. So some

${ }^{37}$ In the case of some more elaborate threats, such as to do something that is a nuisance to someone else, the effort involved in creating the nuisance may be great enough to make execution of the threat rather unlikely.

38 Nozick, "Coercion," 441-445. 
objective standard is required to prevent "coercion" from becoming a catchall term for a common and often trivial form of human interaction.

Some theorists attempt to address the difficulties presented by subjectivity by positing normative criteria that attempt to distinguish coercive threats from those of lesser or different import. For instance, Wertheimer suggests a two-pronged normative test for whether a proposal should count legally as coercive ${ }^{39}$ : first, roughly, the proposal, if executed, must make its recipient worse off than she has a right to be; and second, the recipient must be "entitled to succumb" to the proposal. ${ }^{40}$ Other normative standards could be defined as well. ${ }^{41}$ Such standards aim to offer an objective test for distinguishing threats they will classify as coercive from the plethora of other, unremarkable threats.

If a well-worked-out normative theory were on offer, some augmented version of the pressure approach might yield a largely satisfactory theory of coercion. Perhaps unsurprisingly, however, there is little agreement about what the standard should be, and almost no sustained effort to defend a normative standard as part of a broader more comprehensive normative theory. 42 If there were such an adequate theory, however, it would have to take into consideration factors such as whether the threatener actively accumulates and deploys power over the target in order to make a credible threat, and/or intentionally leverages background power disparities between agents in recognizably different positions of power. The very acts of creating, appropriating and/or leveraging an advantage in power over another for one's own ends surely must figure into an evaluation of the ethical significance of a threat. ${ }^{43}$ So the potential for a moralized account to address the problems of the subjectivity of the pressure approach turns out to depend on the considerations central to the enforcement approach. I would argue, therefore, that any adequate moralized pressure account will have to attend to the same matters that the enforcement approach makes explicit and central to understanding coercion.

39 That is, whether a proposal should "nullify the normal moral and legal effects of one's acts." Coercion, 242.

${ }^{40}$ Wertheimer's discussion of both prongs is extended through chapters 10-17 of Coercion; the quoted phrase is on 307.

${ }^{41}$ Berman analyzes responsibility-defeating coercion similarly to Wertheimer, suggesting that one may be excused for acting due to coercion if "it is thought too demanding to expect her to have refrained from $x$ at the cost of enduring $y$." Berman offers a different normative standard for identifying "wrongful" coercion, viz., that "it involves a threat ... to do what it would be impermissible ... for the threatener to do" (Berman, "Normative Functions," 55). Ryan adopts a similar approach to identifying (wrongful) coercion, but adds to it consideration of whether the act the coercee is dissuaded from was itself morally acceptable: a threat is coercive only if it aims to discourage an act that the coercee was not morally forbidden to perform. Ryan, "The Normative Concept of Coercion," 484.

${ }^{42}$ Wertheimer comes closest, perhaps, to integrating his normative theory of coercion into a broader normative framework, though it pays little attention to the considerations I argue for imminently.

${ }^{43} \mathrm{I}$ argue for this more fully in section $4 \mathrm{~A}$ below. 
Once the factors relevant to the enforcement approach are taken into consideration, however, it becomes doubtful that the subjective, psychological phenomena typically cited in analyses of coercion are still needed to explain the motivational qualities of coercion, or to identify those cases in which a threat carries a significance worth identifying as "coercion." We can understand why coercive threats alter behavior without delving into particular facts about an individual's weighing of specific alterations to their costs and benefits of acting. When one agent can credibly threaten to thwart another's actions broadly, then that agent can reshape the instrumental relations among the things that the threatened agent can do, so as to make meeting the threatener's own particular demands into a necessary means to any other activity the threatened agent might wish to pursue. ${ }^{44}$ Unsurprisingly, this will, in many circumstances, generate significant pressure to do as the powerful agent demands. But whether or not the threatened party feels any such pressure or disadvantage because of the threat, an agent who possesses the power to inhibit broadly another's ability to act can alter the real possibilities for action of those whom he targets, and this itself explains the efficacy of coercive threats. Moreover, because the enforcement approach centers the topic of coercion on the objective fact of how such power is wielded, there is no need for it to invoke moralized or normative criteria to assess the significance of such threats. So while psychological pressure may be a common, instrumental feature of coercive threats, it does not appear to be an essential fact about their efficacy or significance.

To bolster this claim, notice that there are good reasons to dissociate the identification of coercion from the degree of pressure agents feel. Intuitively, one might think that the coerciveness of a threat correlates with the costs of non-compliance, so that a small sanction (a fine, say) is less coercive than a large sanction, and are both less coercive than threats of imprisonment, with shorter imprisonments less coercive than longer. But as the enforcement approach sees things, what makes sanctions such as fines coercive is not the size of the penalties, or the pressure they create for compliance, but the fact that setting and imposing such fines is an exercise of the state's broader powers over the people. 45 Parking fines, for instance, tend to be relatively low; some private associations may impose much larger penalties on members for infractions of their rules. But a system of parking fines differs from a system of penalties of the sort that voluntary associations are generally able to impose in that fines are backed by the state's ability to apply increasing penalties, including the possibility to interdict broadly the activities of scofflaws,

44 The claim that one was coerced into $A$-ing can be read as elliptical for the claim that the coercer has made $A$-ing a necessary means to achieving something else, perhaps even anything else, that is crucial to / necessary for / uneliminable from the coercee's life.

45 This thought develops a suggestion found in J. P. Day in "Threats, Offers, Law, Opinion and Liberty," American Philosophical Quarterly 14 (1977): 257-272. 
more or less without regard to what the scofflaws desire.46 By contrast, in most cases, the potency and enforceability of private associations' penalties on their members depend on how avidly those subject to them want to be members. Although private associations can frustrate such desires by denying someone membership, private associations do not generally wield powers that can ensure their members' compliance if those members are indifferent to remaining in good standing.

At the other end of the spectrum, many threats fail to create significant pressure, despite being nominally significant, because they are associated with demands that are longstanding, perhaps quite reasonable, and in any case are ones that many persons have already accommodated themselves to meeting. Much of the criminal law in well-ordered states falls in this category. To the extent that such law mirrors ordinary norms of justice, most just people are rarely tempted to violate it. Insofar as the law goes beyond the dictates of justice, simple prudence will suffice for most people, most of the time, to adapt their lives to fit within it, at which point the thought of violating most of its dictates may arise only very infrequently. ${ }^{47}$ If one is habituated to following the law, one is unlikely to feel law enforcement as a source of pressure, or to calculate frequently the costs and benefits of violating the law, after such habituation has occurred. Yet the fact that longstanding demands and threats fail to generate continual feelings of pressure hardly gives a reason to deny their coerciveness. To consider one example, very few people in the developed West smoke opium. Of course, many more Westerners would smoke opium than currently do if the sale and use of opium products were not stringently, coercively prohibited. However, it is not the case that most would-be opium smokers frequently, consciously choose not to do so in light of the legal penalties; rather, the option itself is largely missing from most people's mental menu of choices because the state's use of coercion against it makes it rarely feasible or worth considering. ${ }^{48}$ The enforcement approach is therefore of value for explaining how such standing threats are coercive, given their origin in the powers of those who make and enforce them, even though there may be few and mostly indistinct occasions on which any particular agent consciously alters her course in response to them.

Hence, even if coercion is construed narrowly to require the use of threats, the enforcement approach offers a plausible alternative framework

46 If this is doubted, note that anyone can threaten to assess fines for doing any particular act. But such threats are unlikely to cause anyone to alter her behavior, or induce payment of fines, unless there is some elevated, unavoidable consequence to follow at some stage from failure to pay the fines assessed.

47 Obvious exceptions to this generalization arise in cases where the law regulates behavior that is either difficult to change (e.g., due to addiction or sexual orientation) or extremely profitable, or where the law is manifestly unjust.

48 No doubt choices of whether or not to smoke opium are affected by social norms regarding its desirability or reasonability. These norms may of course be affected by many factors, but among them is surely the fact that the state coercively interferes to make opium hard to obtain and to make smoking it incompatible with pursuing many other ends. 
which is sometimes essential for understanding how threats affect behavior their motivational magnitude - in both shorter and longer temporal frameworks. Notably, it does so without appealing to a "baseline" against which threats must be gauged, and without invoking morally normative criteria to set the baseline or to judge the significance of a given threat. Moreover, by changing the focus of our thought about coercion from its effects on the coercee's psychology to the powers of the coercer, we can see that threatening is just one way of using interpersonal power to coerce. Other ways of using such power to block action generally or to shape whole patterns of life and behavior turn out to be equal in importance. Thus the distinction between physically interdicting action and coercive threats to dissuade people turns out to be much less significant than is often suggested.

\section{The Two Approaches Compared in Specific Theoretical Contexts}

The start of this essay noted a number of issues which call for a theoretical understanding of coercion, and claimed that the enforcement approach offered advantages for understanding the workings and significance of coercion. I will now argue in some detail for the relative advantages of the enforcement approach in thinking about some topics where coercion has long been thought to be of importance.

\section{A. The Morality of Coercion 49}

Excepting some anarchists, almost everyone else thinks coercion is sometimes justified. Yet this prompts the question why coercion requires special justification, why coercion is thought to be an act of special moral significance in a way that, e.g., using persuasion or offering incentives are generally unproblematic. While this is perhaps less puzzling if we are asking about direct uses of force and violence (as the enforcement approach would support), there is a challenge for a pressure account to explain what makes stating a conditional threat a matter of moral questionability and of moral significance, even when a use of coercion proves to be justified. I will argue that, unless one takes account of factors central to the enforcement approach, at least some significant aspects of the moral significance of coercion will be unmarked and unexplainable.

What can the pressure approach say to explain coercion's significance? As argued earlier, it is rather unremarkable for one agent merely to state that he will act in a way disadvantageous to another if that agent fails to meet some announced condition; making such statements is involved in many different activities (such as a teacher setting a rule that penalizes late homework) that could be counted as coercion only at a cost of emptying the concept of any ethical or political usefulness. Furthermore, it is not obvious why stating

49 The arguments of this section are a digest of the more thorough treatment in Scott A. Anderson, "On the Immorality of Threatening," forthcoming in Ratio. 
that one will in the future do harm to someone is itself of any great ethical consequence. Stating that one will do something does not make it the case that one will do it; it may not even make it more likely. Of course, as a result of stating such a threat, one may thereby accrue ill-gotten gains if, say, the threatened party hands over her wallet. But the objection to the use of threats is not only that they might be used to achieve unjust results. The use of threats makes getting ill-gotten gains more ill - for instance, it turns a theft into a robbery, which is a more serious crime. Moreover, the effects brought about by threatening may well be beneficial, if for instance the coercer is a paternalist with the coercee's best interests at heart. So the ethical worry about threatening appears to be distinct from whatever ill effects a threat may produce.

One might claim that the problem with stating a conditional threat is that it causes psychological discomfort - because it involves pressure - and so this is what is significant about it. Yet in general it is a good thing when agents feel pressure to do what is in their best interest, in proportion to the degree of benefit or harm at stake. Moreover, it is rare to hear (sincere) ethical complaints that someone has made an offer too tempting. Though one may find the fear of loss harder to bear, again, we have reason to want to be appraised of harms that may befall us so that we may avoid them, just as we seek accurate forecasts for hurricanes and earthquakes. So creating pressure or fear is also ethically mundane in at least some ordinary cases.

One might then wonder whether it is the threatener's intention to cause such pressure, or harm, that is morally significant. But this may not be the threatener's intention at all; it may be merely accidental to his other goals (which may again be paternalistically aimed at the threatened party's good, too). Even if one agent threatens another in a way that he knows creates some fear of loss or pressure on the other, this still is not obviously problematic. Agents often interact in ways that they know will negatively affect the expected utilities of others. It takes relatively special circumstances (say, a contract or other specific right) to give one party a claim to reap particular rewards from certain actions, and a claim against others who might lower them. This might suggest again that a normative account of coercion is required, which might hold that coercive threats are objectionable because they portend a violation of another's rights, and it is this, or this combined with a lowering of expected utility, that makes them morally objectionable. Still, even if a normative analysis avoids begging the question (which is not certain), it will fail to account for the moral significance of many cases in which coercion is thought to take place. Although some threats may violate rights, it is apparent that they do not always do so: the law's generic threat to incarcerate law breakers would not ordinarily count as a threat to violate their rights. So either we would need to deny that such threats, however serious, are co- 
ercive, ${ }^{50}$ or else a moralized account will fail to elucidate their moral significance.

As a last try, if we allow that threatening to do wrong is itself wrongful, one might suggest that coercion just is acting wrongfully to create pressure on another's will, and that this combination captures what is significant about coercion, morally speaking. ${ }^{51}$ To see that this still falls short, compare coercive threatening with giving a fraudulent warning, in which P declares, credibly though falsely, that Q's utility will be adversely affected (for reasons independent of P's agency) if Q does (not do) A. Under some circumstances, such a false warning might create pressure on $\mathrm{Q}$ equal to that created by P's threat to harm Q, and so would likewise be a kind of wrongfully created psychological pressure. Yet there are good reasons to think coercive threats present a more serious moral worry. Fraudulent warnings can create epistemic problems for someone who is deceived, but the power to deceive does not generally imply the power to create broad disabilities for the deceived party. Hence, for instance, a deceived party might still remedy her problem through such activities as conducting due diligence, seeking outside advice or investigating the trustworthiness of the agent giving the warning. Outsiders can offer advice or education. By contrast, the power to threaten credibly typically implies a much greater subjection of coercee to coercer. So, for instance, coercion generally disables (or threatens to disable) its target from being able to take effective countermeasures, or renders him unlikely to succeed or dangerously imprudent.

These arguments suggest that the ethical significance of coercive threats depends not (just) on the pressure they generate, nor (just) on the particular acts they inhibit or induce, but rather on the fact that they involve manufacturing or appropriating and then leveraging a much broader power differential between coercer and coercee - where that power is usually generic in its potency, suited to work against almost any agent, and employable for a wide range of ends - which explains why it is particularly attractive to criminals, as well as to the state. Lucas suggests, in the passage cited early on, that the ability to prevent action broadly by individuals is of central importance for social organization, and a factor of importance in virtually everyone's life. While various forms of influence and deceptive practices no doubt are worth attending to as well, there is a crucial qualitative difference between, on the one hand, attempting to sway behavior through advice, evidence, emotive appeals, rewards, discomfort or disapproval and, on the other hand, using powers that are suited to stop a person from pursuing her aims regardless of her motives or reasons. Even fraud and deception are typically less dangerous and onerous in most of their uses. So while there is value in tracking many different forms of power, the ability to interfere with or obstruct broadly the actions of another is a power that is of particular social and ethical import,

${ }^{50}$ See Edmundson, "Is Law Coercive?" and Three Anarchical Fallacies.

${ }^{51}$ Berman takes this route in defining morally wrongful coercion in "Normative Functions." 
and one that deserves special monitoring and regulation. Hence the enforcement approach to coercion gives a clearer and more helpful picture of what is at stake in the use of coercion than any account that focuses on pressure as the essence of coercion.

\section{B. Coercion and State Authority}

Only a few recent coercion theorists have directly challenged the connection between state authority (and by extension legitimacy) and the state's monopolization of the right to use coercion, but it would follow from the accounts of most others that they should do likewise. Both moralized and nonmoralized accounts of coercion obscure this connection, though for different reasons. Non-moralized pressure accounts tend to make coercion out to be a fairly mundane, common activity, such that no state could reasonably purport to need or to exercise a monopoly on its use. A state may of course have reason to check some kinds of threats (say, those involving weapons), or some uses of them (say, blackmail), but states need not check all of the different forms of pressuring in order to secure domestic peace and tranquility, nor does their authority depend on doing so. On the other hand, if, as some moralized accounts suggest, "coercion" refers only to those threats the making of which violates morality or rights or some other normative standard, it is hard to see how the use of threats by a just, well-ordered state would count as coercive: after all, threatening to imprison those who violate the law does not seem to threaten to violate their rights. So, as William Edmundson has argued (following the lines of Alan Wertheimer's moralized account of coercion), law appears not to be coercive. ${ }^{52}$

Nonetheless, it can be of both practical and theoretical use to be able to strike a line between coercive and non-coercive interaction. Such a line can help determine whether state intervention is warranted to protect some individuals from others, and whether it is legitimate to hold someone to account for failing to follow the law. People who are subject to forceful or violent coercive impositions by others will need either to protect themselves or to have the protection of a system of justice that regulates such coercion. A state that wishes to claim legitimate authority will need to protect individuals from the coercion of others as well as to avoid unjust coercion of its own. If people are not able to depend on state protection against the coercion of others, this has long been thought to reduce or eliminate the state's authority to command those people, since in effect a new sovereign has taken up reign over them, or at least they may of necessity have to establish such a new sovereign in order to gain protection against those who threaten them.

52 Edmundson, "Is Law Coercive?" and Three Anarchical Fallacies. Also sharing this view is Vinit Haksar, "Coercive Proposals: Rawls and Gandhi," Political Theory 4 (1976): 65-79. Though it does not restrict its view of coercion to merely the use of pressure, this nonstandard view seems to me to be unavoidable for Arthur Ripstein's account of the relationship of the state to coercion in his Kant-inspired "Authority and Coercion," Philosophy and Public Affairs 32 (2004): 2-35. 
The enforcement approach to coercion helps explain the importance of the state's ability to monopolize the right to the use of the sorts of powers it associates with coercion. Society as a whole needs to be able to prevent and inhibit various forms of disruptive, anti-social behaviour (e.g., murder, theft, rape) in order to provide the basic stability and safety that allow strangers to live in relatively cooperative and harmonious interaction with one another. While most people will likely respond to either moral or prudential considerations that favor peaceful coexistence, there are continual temptations for some people to victimize others. When individuals or groups disregard law, morality and prudence, and cause mayhem or employ coercion themselves, society will need to be able to check and discourage such behavior effectively. Force and violence, including threats of such, seem to be indispensible tools for this work. Many who are tempted to behave disruptively may be discouraged by the threat of legal interdiction; those who are not dissuaded by such threats can be incarcerated as a means of preventing further infractions. Hence it is crucial to a state's function and authority that it exercise such powers, and regulate their accumulation and exercise by others within its borders.

\section{Coercion and Responsibility}

The question to which pressure accounts have been most assiduously applied is how coercion affects various sorts of responsibility for action. ${ }^{53}$ As Alan Wertheimer's extensive study shows, there are a wide variety of contexts in which questions of responsibility arise, and differences amongst these contexts may require specific nuances to capture either our historical practices or intuitions regarding coercion. And in general it seems that, unless one defines coercion in terms of the disruption of responsibility, to be coerced is neither always necessary nor always sufficient to curtail an individual's responsibility for acts taken under coercion. Hence I believe Wertheimer is right that the effect of coercion on responsibility is highly context-sensitive, and that judgment in this domain may be impossible without normative presuppositions. Thus the enforcement approach could not, without supplementation, explain whether and how coercion affects responsibility for coerced acts.

That said, if coercion per se has an effect on responsibility that is distinct from that of other kinds of pressure on decisions (as is often supposed), then the enforcement approach offers some advantages over pressure accounts for understanding why that should be so. First, in explaining how credible coercers are able to put pressure on coercees via threats, the enforcement approach provides an objective picture of how credible coercers are able to reconfigure the coercee's space of options, which then also explains why we might transfer responsibility from coercee to coercer. Second, and more interestingly, it provides a basis for a specific objection to private coercion that

53 There are many senses of responsibility at issue here, but since my intended intervention is quite limited, it will not pay to take up the distinctions among them. 
distinguishes its effect on responsibility from that of other pressures created by individuals, society and natural causes. I argued above that a state's authority depends on its ability to monopolize and regulate coercion among its subjects, because individuals need protection and stability against unpredictable, private uses of such power. If so, then private, unauthorized uses of coercion constitute a failure of the state to protect its subjects in accord with the conditions of its authority, thus leaving them to engage in self-help, such as acceding to the demands made by those private coercers. When a state has failed to protect its inhabitants from private, unauthorized coercion, it would seem unjust for a state nonetheless to hold coercees to account for actions taken under coercion. It may also be counterproductive to the state's aims, as it would incentivize individuals to engage in pre-emptive self-help, in order to defend themselves against possible coercion, and thus further increase the potential for private parties to engage in coercion against one another. Thus the state's role as monopolist and regulator of the right to use coercion gives a reason specific to coercion (as distinct from other forms of pressure on or interference with action) for why states should limit the responsibility of individuals for their coerced actions. But, as argued above, this claim depends on seeing coercion as the enforcement approach does: as an agent's directed use of socially significant power.

\section{Conclusion}

There is use for a concept that tracks the specific form of power that is familiarly associated with the term "coercion" as it has long been used in political philosophy. The recent philosophical trend away from this understanding indicates that the traditional meaning of "coercion" is perhaps not as obvious or well understood as one would wish. But if I have succeeded here in setting out the resources inherent in the traditional enforcement account, it should help to bolster it against some of the most frequent misunderstandings and apparent difficulties it encounters. In doing so, I hope also to have shown that coercion remains a category well worth a political philosopher's focused attention, because it is distinctive among the various ways humans can relate to and influence each other. It thus deserves to be treated as a fundamental element in political and ethical theory, with boundaries that, while not razor sharp, are much more clearly defined than is sometimes thought.

Scott A. Anderson

University of British Columbia

Department of Philosophy

scottand@interchange.ubc.ca 